\title{
Interfacial stresses in externally FRP-plated structures: effect of shear deformations and fiber orientation
}

\author{
Bachir Kerboua ${ }^{1,2, a}$, El Abbès Adda Bedia ${ }^{1,3}$ And Abdelouahad Tounsi ${ }^{1,3}$ \\ 1 Laboratoire des Matériaux et hydrologie, Université de Sidi Bel Abbés BP 89, Cité Ben M’hidi, 22000 Sidi Bel Abbés, Algeria \\ 2 Université de Tlemcen, Faculté des Sciences de l'Ingénieur, Algeria \\ 3 Université de Bel Abbés, Faculté des Sciences de l'Ingénieur, Algeria
}

Received 8 October 2007, Accepted 31 March 2009

\begin{abstract}
The composite fiber materials of polymers (FRP) have physical properties, which are exploited recently for the reinforcement and rehabilitation of the structures, in mechanical, civil engineering and biomedical field, subjected to degradation or default risks. Since a beam without any form of reinforcement will fail when subjected to a relatively small tensile load. Therefore the use of the FRP to strengthen the structures is an effective solution to increase the overall strength technique. In this paper, a new theoretical approach model to estimate shear and peel-off stresses is proposed. Axial stresses and bending moment coupled with shear deformation and thermal effect in an FRP-strengthened beam are considered, including the variation in FRP plate fiber orientation.
\end{abstract}

Key words: Interfacial stresses / FRP composites / Strengthening / Thermal stress / Fibers

Résumé - Contraintes interfaciales des structures renforcées par composites FRP : effet de deformations de cisaillements et de l'orientation des fibres. Les composites (FRP) ont des propriétés physiques qui sont exploitées récemment pour le renforcement et la réhabilitation des structures soumises à des risques de dégradations externes (dans le domaine de mécanique, génie civil ou biomédical...). Les structures sans renforcement seront fragiles à toutes sortes de sollicitations externes. Cependant, l'utilisation des fibres en polymères est une nouvelle technique qui permet aux structures d'avoir une rigidité et une résistance supplémentaire. Dans ce travail, on donne une approche originale qui permet de déterminer les contraintes interfaciales en tenant compte non seulement des effets de charge mécaniques et thermique mais, aussi des effets de déformations de cisaillement et de l'orientation des fibres. Les résultats numériques montrent l'avantage de cette étude sur celles précédemment étudiées dans la littérature.

Mots clés : Contraintes interfaciales / FRP composites / Renforcement / Contraintes thermiques / Fibres

\section{Introduction}

Over the past several decades, extensive research and development in the field of materials engineering and science have been carried out with fiber-reinforced plastic (FRP) composites leading to a wide range of practical applications $[1,2]$. Conventional rehabilitating techniques using stitching and steel reinforcing patch design provide a promising strengthening solution in civil applications [3]. Unfortunately, the weight penalty, labor intensive application, and subsequent corrosion of the steel material may eventually increase the overall maintenance cost [4]. Accordingly, this drives the development and

\footnotetext{
a Corresponding author: kerbouac@yahoo.fr
}

application of new materials and technologies, which extend the service life of many structures, such as strengthening of structures to carry greater traffic loads, to cope with change of use, to rectify design faults, and for repair. Thus, the use of FRP materials is becoming increasingly important for extending the service life of our civil construction facilities into the 21st century [5]. Steel plate bonding is recognized as an effective solution for reinforcing or strengthening structure elements in order to minimize the risk of concrete cracking, which may result in the corrosion of embedded steel reinforcement. The use of FRP in upgrading and strengthening structures has been accepted gradually only in recent years. In the past, FRP materials were used primarily in the aerospace and defense industries rather than in civil construction areas, 

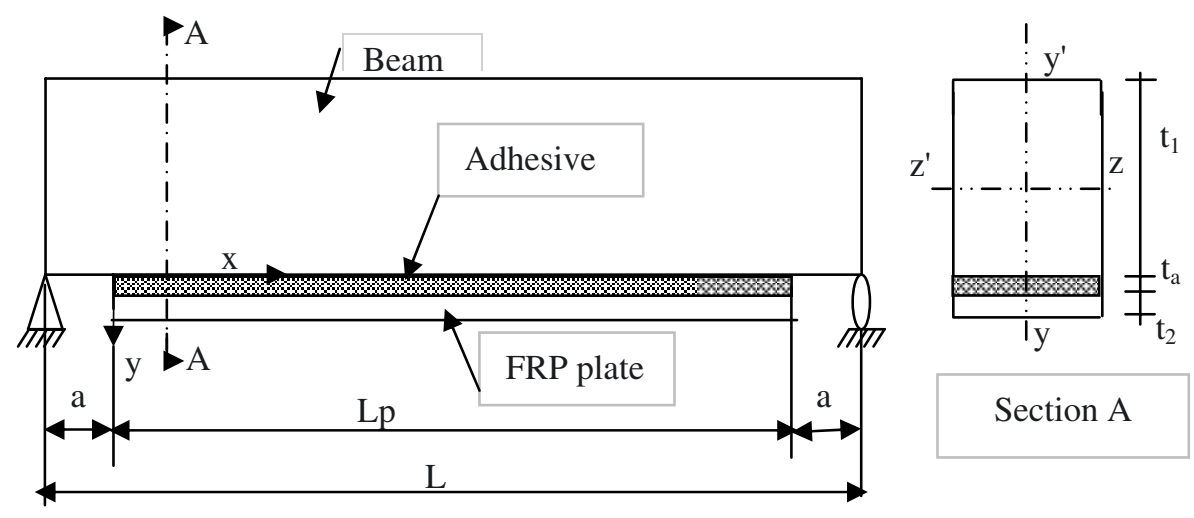

Fig. 1. Simply supported beam strengthened with bonded plate.

mainly due to the prohibitively high cost of raw materials and manufacturing processes. Previous researches show that glass fiber composites could be effectively used for concrete beam strengthening, resulting in the improvement of flexural load carrying capacity [6-10]. Among all different types of structure strengthening methods, the use of FRP materials for tension face strengthening techniques presents better strengthening characteristic of the ultimate flexural load capacity [11-28]. This paper introduces an original theoretical model for estimating adhesive shear and peel-off stresses and the shear deformations coupled with the thermal effect of an externally bonded FRP plate on the beam tension interface, with different fiber orientations laminate layers, and mechanical properties of the FRP and adhesive materials.

The solution presented by Smith and Teng [21] seems to be the more accurate widely applicable solution, particularly when the flexural stiffness of the bonded plate becomes significant. A disadvantage of this solution is that the thermal and shear deformations effect and the FRP plate fiber orientation are not included in the method. These parameters are also not taken into consideration by the other approximate closed-form solutions. Lau et al. [22] have presented a simple theoretical model to estimate the interfacial stresses, in which the FRP plate fiber orientation is considered. However this method ignores the effects of bonding deformations in the plate, the thermal and the shear deformations effect. On the other hand, the flexural rigidity of the composite plate is not well estimated to compute the interfacial normal stress. Rabinovich and Frostig [23] have presented a higher order experiments analysis in which the adhesive layer was treated as an elastic medium with negligible longitudinal stiffness. This leads to uniform stresses and linearly varying normal stresses through the thickness of the adhesive layer. The significance of their solution is that it is the first solution that satisfies the stress-free boundary condition at the ends of the adhesive layer. Using the same approach, they investigated the effects of an uneven adhesive layer [24] and material non linearity [25]. They also evaluated the energy release rate to predict debonding failure. Shen et al. [26] proposed an alternative analytical complementary energy approach, which resulted in closed-form expressions. [27,28] proposed an alternative analytical shear deformations approach, which resulted a simple expression. The simple approximate closed-form solutions discussed in this paper provide a useful but simple tool for understanding the interfacial behaviour of an externally bonded FRP plate on the beam with the consideration of shear deformations coupled with the thermal and the fiber orientation effect.

\section{Research significance}

The most common failure modes for FRP- strengthened beams are debonding or ripping of the FRP plate. Both of these premature failure modes are caused by interfacial stress concentrations in the adhesive layer. Closed-form solutions of such stress are thus required in developing design guidelines for strengthening reinforced concrete beams with FRP plates or all kind's material.

\subsection{Theoretical approach}

The derivation of the new solution below is described terms of adherends 1 and 2, see Figure 1, where adherend 1 is the beam and adherend 2 is the soffit plate. Adherend 2 can be either steel or FRP but not limited to these two. A schematic illustration of a theoretical model for evaluating adhesive stress transfer properties for the current study is shown in Figures 1 and 2. The following assumptions are used to simplify the calculations:

1. the beam, adhesive, and FRP materials behave elastically, linearly and isotropically;

2. No slip is allowed at the interface of the bond (i.e. there a perfect bond between the FRP plate and the beam);

3. stresses in the adhesive layer and FRP plate do not change with thickness because it is assumed that both the adhesive and composite materials are very thin;

4. deformations of adherends 1 and 2 are due to bending moments, axial forces, thermal load and shear deformations; 


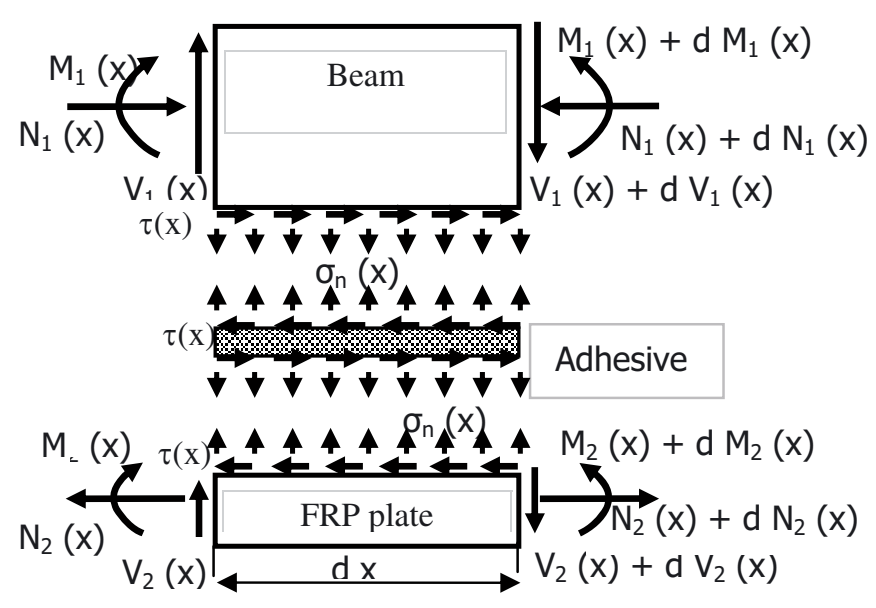

Fig. 2. Forces in infinitesimal element of soffit-plated beam.

5. the shear stress analysis assumes that the curvatures in the beam and plate are equal. However, this assumption is not made in the normal stress solution.

\section{Shear stress distribution}

Figure 2 shows an infinitesimal element of a beam with a reinforced FRP plate. In Figure 2, $V, M$ and $N$ are the shear force, the bending moment and the longitudinal tension, respectively, $\tau$ and $\sigma$ the shear stress and the normal stress at the interface, respectively, and $t$ the component thickness. The subscripts 1 and 2 denote beam, adhesive and FRP plate, respectively. This notation will be used throughout the paper. From assumption 4, the shear force and the longitudinal tension in the adhesive can be considered.

A differential segment of a plated beam is shown in Figure 2, where the interfacial shear and normal tresses are denoted by $\tau(x)$ and $\sigma(x)$, respectively. Figure 2 also, shows the positive sign convention for the bending moment, shear force, axial force and applied loading. In Figures 1 and 2, the shear strain in the adhesive layer can be written by equation (1)

$$
\gamma=\frac{\mathrm{d} u(x, y)}{\mathrm{d} y}+\frac{\mathrm{d} v(x, y)}{\mathrm{d} x}
$$

where $u(x, y)$ and $v(x, y)$ are the horizontal and vertical displacements respectively at any point in the adhesive layer as defined in Figure 1. The corresponding shear stress is given as

$$
\tau=G_{a}\left(\frac{\mathrm{d} u(x, y)}{\mathrm{d} y}+\frac{\mathrm{d} v(x, y)}{\mathrm{d} x}\right)
$$

where $G_{a}$ is the shear modulus of the adhesive layer. Differentiating the above expression with respect to $x$ gives

$$
\frac{\mathrm{d} \tau}{\mathrm{d} x}=G_{a}\left(\frac{\mathrm{d}^{2} u(x, y)}{\mathrm{d} y \mathrm{~d} x}+\frac{\mathrm{d}^{2} v(x, y)}{\mathrm{d} x \mathrm{~d} y}\right)
$$

The second term $\frac{\mathrm{d}^{2} v(x, y)}{\mathrm{d} x \mathrm{~d} y}$ in equation (3) represents the deviations of the vertical displacement. It is a small term that one disregards it in relation to the first defined term that represents the deviations of the horizontal displacement, in order to facilitate the numeric resolution, see assumption 5 . The adhesive layer is assumed to be subjected to uniform shear stresses and therefore $u(x, y)$ must vary linearly across the adhesive thickness $t_{a}$, then, the first term in equation (1) can be written

$$
\frac{\mathrm{d} u}{\mathrm{~d} y}=\frac{1}{t_{a}}\left(u_{2}(x)-u_{1}(x)\right)
$$

Differentiating equation (4)

$$
\frac{\mathrm{d}^{2} u(x, y)}{\mathrm{d} y \mathrm{~d} x}=\frac{1}{t_{a}}\left(\frac{\mathrm{d} u_{2}(x)}{\mathrm{d} x}-\frac{\mathrm{d} u_{1}(x)}{\mathrm{d} x}\right)
$$

$u 1(x)$ and $u 2(x)$ are the longitudinal displacements at the base of adherend 1 and the top of adherend 2, respectively, and $t \mathrm{a}$ is the thickness of the adhesive layer.

The strains at the base of adherend 1, considering all components of axial, bending, shear deformations and thermal effect, are given as.

$$
\frac{\mathrm{d} u_{1}}{\mathrm{~d} x}=\varepsilon_{1}(x)=\alpha_{1} \Delta T+\frac{M_{1} t_{1} / 2}{E_{1} I_{1}}+\frac{N_{1}}{E_{1} A_{1}}-\frac{t_{1}}{3 G_{1}} \frac{\mathrm{d} \tau(x)}{\mathrm{d} x}
$$

The strains at the base of adherend 2 , considering all components of axial, bending, shear deformations and thermal effect, and the composite laminate witch is an orthotropic material and its material properties vary from layer to layer. In current study, the laminate theory is used to determine the strain behaviours of the externally bonded composite plate in order to investigate the whole mechanical performance of the composite-strengthened structure $[29,30]$.

$$
\begin{aligned}
& {\left[\varepsilon^{0}\right]_{2}=\left[A^{x}\right][N]_{2} \frac{1}{b_{2}}} \\
& {[k]=\frac{z}{b_{2}}\left[D^{x}\right][M]_{2}} \\
& {[k]=\left[\begin{array}{c}
k_{x} \\
k_{y} \\
k_{x y}
\end{array}\right], \begin{array}{l}
\text { are the plane strains curvature of the } \\
\text { FRP plate }
\end{array}}
\end{aligned}
$$

$$
\left[\varepsilon^{0}\right]_{2}=\left[\begin{array}{c}
\varepsilon_{x} \\
\varepsilon_{y} \\
\varepsilon_{x y}
\end{array}\right], \begin{aligned}
& \text { are the plane strains vector of the } \\
& \text { FRP plate }
\end{aligned}
$$

$[N]_{2}=\left[\begin{array}{c}N_{x} \\ N_{y} \\ N_{x y} l\end{array}\right]$, are the axial forces of the FRP plate

$\left[A^{x}\right]=\left[A^{-1}\right]$, is the inverse of the extensional matrix

$\left[D^{x}\right]=\left[D^{-1}\right]$, is the inverse of the flexural matrix 
In the present study, only an axial load $N x$ and the bending moment $M x$ in the beam's longitudinal axis are considered, i.e. $N y=N x y=0$ and $M y=M x y=0$. Therefore the strain at the top of the FRP plate is given by equation (14)

$\varepsilon_{2}(x)=A_{11}^{x} N_{2}(x) \frac{1}{b_{2}}-\frac{Z_{2}}{b_{2}} D_{11}^{x} M_{2}(x)+\frac{t_{2}}{3 G_{2}} \frac{\mathrm{d} \tau(x)}{\mathrm{d} x}+\alpha_{2} \Delta T$

$\frac{t_{1}}{3 G_{1}} \frac{\mathrm{d} \tau(x)}{\mathrm{d} x}$ and $\frac{t_{2}}{3 G_{2}} \frac{\mathrm{d} \tau(x)}{\mathrm{d} x}$, are the terms of the distortion of the structure and the plate, under the action of the shear deformations $[27,28]$.

$E$ is the elastic modulus, $G$ is the shear modulus, $b_{2}$ is the width of the soffit plate, $A$ the cross-sectional area, $I$ is the second moment of area A, $Z_{2}$ is the is the thickness of the plate. The subscripts 1 and 2 denote adherends 1 and 2, respectively. $M(x), N(x)$ and $V(x)$ are the bending moment, axial and shear forces in each adherend while $y_{1}$ and $y_{2}$ are the distances from the bottom of adherend 1 and the top of adherend 2 to their respective centroid.

An horizontal equilibrium of the adherends 1 and 2 gives:

$$
\frac{\mathrm{d} N_{2}(x)}{\mathrm{d} x}=\tau(x) b_{2}
$$

and

$$
\frac{\mathrm{d} N_{1}(x)}{\mathrm{d} x}=\tau(x) b_{2}
$$

Integrating equations (15) and (16), gives

$$
N_{1}(x)=N_{2}(x)=N(x)=b_{2} \int_{0}^{x} \tau(x) \mathrm{d} x
$$

Assuming equal curvature in the beam and the soffit plate, the relationship between the moments in the two adherends can be expressed as

$$
M_{1}(x)=R M_{2}(x)
$$

with

$$
R=\frac{E_{1} I_{1} D_{11}^{x}}{b_{2}}
$$

Moment equilibrium of the differential segment of the plated beam in Figure 2, related to the reference $(x, y)$, gives

$$
M_{T}(x)=M_{1}(x)+M_{2}(x)+N(x)\left[y_{1}+y_{2}+t_{a}\right]
$$

The bending moment in each adherend expressed as a function of the total applied moment and the interfacial shear stress, is given as

$$
\begin{aligned}
& M_{1}(x)=\frac{R}{R+1}\left[M_{T}(x)-b_{2} \int_{0}^{x} \tau(x)\left(y_{1}+y_{2}+t_{a}\right) \mathrm{d} x\right] \\
& M_{2}(x)=\frac{1}{R+1}\left[M_{T}(x)-b_{2} \int_{0}^{x} \tau(x)\left(y_{1}+y_{2}+t_{a}\right) \mathrm{d} x\right]
\end{aligned}
$$

The first derivative of the bending moment equation in each adherend gives

$$
\begin{aligned}
& \frac{\mathrm{d} M_{1}(x)}{\mathrm{d} x}=\frac{R}{R+1}\left[V_{T}(x)-b_{2} \tau(x)\left(y_{1}+y_{2}+t_{a}\right)\right] \\
& \frac{\mathrm{d} M_{2}(x)}{\mathrm{d} x}=\frac{1}{R+1}\left[V_{T}(x)-b_{2} \tau(x)\left(y_{1}+y_{2}+t_{a}\right)\right]
\end{aligned}
$$

Substituting equations (6) and (14) into equation (5) gives

$$
\begin{aligned}
\frac{\mathrm{d} \tau}{\mathrm{d} x}= & \frac{G_{a}}{t_{a}}\left(\Delta T\left(\alpha_{2}-\alpha_{1}\right)+\frac{D_{11}^{x} M_{2} t_{2}}{2 b_{2}}+\frac{A_{11}^{x} N_{2}}{b_{2}}\right. \\
& -\frac{M_{1} t_{1} / 2}{E_{1} I_{1}}-\frac{N_{1}}{E_{1} A_{1}}-\frac{\mathrm{d} \tau}{\mathrm{d} x}\left(\frac{t_{2}}{3 G_{2}}+\frac{t_{1}}{3 G_{1}}\right)
\end{aligned}
$$

Differentiating equation (25) gives

$$
\begin{array}{r}
\frac{\mathrm{d}^{2} \tau(x)}{\mathrm{d} x^{2}}=\frac{G_{a}}{t_{a}}\left(\frac{D_{11}^{x} t_{2} \mathrm{~d} M_{2}(x)}{2 b_{2} \mathrm{~d} x}+\frac{A_{11}^{x} \mathrm{~d} N_{2}(x)}{b_{2} \mathrm{~d} x}-\frac{t_{1} d M_{1}}{2 E_{1} I_{1} d_{x}}\right) \\
+\frac{G_{a}}{t_{a}}\left(-\frac{\mathrm{d} N_{1}(x)}{\mathrm{d} x} \frac{1}{E_{1} A_{1}}-\frac{\mathrm{d}^{2} \tau(x)}{\mathrm{d} x^{2}}\left(\frac{t_{1}}{3 G_{1}}+\frac{t_{2}}{3 G_{2}}\right)\right)
\end{array}
$$

Substituting each term of equations (15), (16), (23) and (24), into equation (26) gives the following governing differential equation (27) for the interfacial shear stress:

$$
\begin{aligned}
\frac{\mathrm{d}^{2} \tau(x)}{\mathrm{d} x^{2}} & -K_{1} b_{2}\left(\frac{\left(y_{1}+y_{2}\right)\left(y_{1}+y_{2}+t_{a}\right) D_{11}^{x}}{E_{1} I_{1} D_{11}^{x}+b_{2}}\right. \\
& \left.+\frac{1}{E_{1} A_{1}}+\frac{A_{11}^{x}}{b_{2}}\right) \tau(x) \\
& +K_{1}\left(\frac{y_{1}+y_{2}}{E_{1} I_{1} D_{11}^{x}+b_{2}} D_{11}^{x}\right) V_{T}(x)=0
\end{aligned}
$$

with

$$
K_{1}=\frac{1}{\left(\frac{t_{a}}{G_{a}}+\frac{t_{2}}{3 G_{2}}+\frac{t_{1}}{3 G_{1}}\right)}
$$

The general solutions presented below is given by equation (27)

$$
\begin{aligned}
\tau(x)= & B_{1} \cosh (\lambda x)+B_{2} \sinh (\lambda x)+m_{1} V_{T}(x) \\
\lambda^{2}= & K_{1} b_{2}\left(\frac{\left(y_{1}+y_{2}\right)\left(y_{1}+y_{2}+t_{a}\right) D_{11}^{x}}{E_{1} I_{1} D_{11}^{x}+b_{2}}\right. \\
& \left.+\frac{1}{E_{1} A_{1}}+\frac{A_{11}^{x}}{b_{2}}\right) \\
m_{1}= & \frac{K_{1}}{\lambda^{2}}\left(\frac{y_{1}+y_{2}}{E_{1} I_{1} D_{11}^{x}+b_{2}} D_{11}^{x}\right) .
\end{aligned}
$$

\section{Application of boundary conditions}

Having derived the general solutions for the interfacial shear and normal stresses, one load case is now considered. A simply supported beam is investigated which is 
subjected to a uniformly distributed load. This section derives the expressions of the interfacial shear and normal stresses for this load case by applying suitable boundary conditions.

By substituting the expression for the shear force in a simply supported beam subjected to a uniformly distributed load into equation (29), the general solution for the interfacial shear stress for this load case can be found as

$\tau(x)=B_{1} \cosh (\lambda x)+B_{2} \sinh (\lambda x)+m_{1} q\left(\frac{L}{2}-x-a\right)$

$o \leq x \leq L_{p}$

where $q$ is the uniformly distributed load and $x, a, L$ and $L_{P}$, defined in Figure 1. The constants of integration need to be determined by applying suitable boundary conditions. The first boundary condition is the applied bending moment at $x=0$. Here, the moment at the plate end $M 2(0)$ and the axial force of either the beam or the soffit plate $N 1(0)=N 2(0)$ are zero. As a result, the moment in the section at the plate curtailment is resisted by the beam alone and can be expressed as

$$
M_{1}(0)=M_{T}(0)=\frac{q a}{2}(L-a)
$$

Substituting equations (6) and (14) with the effects of shear lag considered into equation (5), and applying the above boundary condition, gives

$$
\begin{aligned}
\left.\frac{\mathrm{d} \tau(x)}{\mathrm{d} x}\right|_{x=0}= & \frac{G_{a}}{t_{a}}\left(\frac{-y_{1}}{E_{1} I_{1}} M_{1}(0)+\left(\alpha_{2-} \alpha_{1}\right) \Delta T\right. \\
& \left.-\left.\frac{t_{2}}{3 G_{2}} \frac{\mathrm{d} \tau(x)}{\mathrm{d} x}\right|_{x=0}-\left.\frac{t_{1}}{3 G_{1}} \frac{\mathrm{d} \tau(x)}{\mathrm{d} x}\right|_{x=0}\right)
\end{aligned}
$$

For practical cases the expression can be simplified to

$$
\begin{aligned}
\left.\frac{\mathrm{d} \tau(x)}{\mathrm{d} x}\right|_{x=0} & =k_{1}\left(\frac{-y_{1}}{E_{1} I_{1}} M_{1}(0)+\left(\alpha_{2}-\alpha_{1}\right) \Delta T\right) \\
K_{1} & =\frac{1}{\left(\frac{t_{a}}{G_{a}}+\frac{t_{2}}{3 G_{2}}+\frac{t_{1}}{3 G_{1}}\right)}
\end{aligned}
$$

By substituting the derivative of equation (35) into equation (32), B2 can be determined as

$$
B 2=-\frac{K_{1}}{\lambda}\left[\frac{y_{1}}{E_{1} I_{1}} M_{T}(0)+\left(\alpha_{1}-\alpha_{2}\right) \Delta T\right]+\frac{m_{1} q}{\lambda}
$$

The second boundary condition requires zero interfacial shear stress at mid-span due to symmetry of the applied load. $B 1$ can therefore be determined as

$B_{1}=+\frac{K_{1}}{\lambda}\left[\frac{y_{1}}{E_{1} I_{1}} M_{T}(0)+\left(\alpha_{1}-\alpha_{2}\right) \Delta T\right]-\frac{m_{1} q}{\lambda}=-B_{2}$

\section{Distribution of the interfacial normal stress}

The governing differential equation for the interfacial normal stress is derived in this section. The distribution of the normal stress along the structure interfacial and composite plate, according to a constant section, is determined by the method presented follows, and integrating the thermal load coupled with the model of the shear deformations [14-18].

The normal stress in the adhesive can be expressed according to the following hypothesis.

$$
\sigma_{n}(x)=K_{n} \Delta w(x)=K_{n}\left[w_{2}(x)-w_{1}(x)\right]
$$

$K_{n}$ is the normal rigidity of adhesive per unit of length. $w_{1}(x)$ and $w_{2}(x)$ are the vertical displacements of adherends 1 and 2, respectively.

Differentiating equation (39) twice, it results,

$$
\frac{\mathrm{d}^{2} \sigma_{n}(x)}{\mathrm{d} x^{2}}=K_{n}\left[\frac{\mathrm{d}^{2} w_{2}(x)}{\mathrm{d} x^{2}}-\frac{\mathrm{d}^{2} w_{1}(x)}{\mathrm{d} x^{2}}\right]
$$

Relation of the moment and curvature of the beam and the composite give equations (41) and (42)

$$
\begin{aligned}
& \frac{\mathrm{d}^{2} w_{1}(x)}{\mathrm{d} x^{2}}=-\frac{M_{1}(x)}{E_{1} I_{1}} \\
& \frac{\mathrm{d}^{2} w_{2}(x)}{\mathrm{d} x^{2}}=-\frac{D_{11}^{x} M_{2}(x)}{b_{2}}
\end{aligned}
$$

Equilibrium consideration of the beam and FRP plate gives the relations between moments and shear loadings

$$
\begin{aligned}
& \frac{\mathrm{d} M_{1}(x)}{\mathrm{d} x}=V_{1}(x)-b_{2} y_{1} \tau(x) \quad \text { and } \\
& \frac{\mathrm{d} V_{1}(x)}{\mathrm{d} x}=-b_{2} \sigma(x)-q(x) \\
& \frac{\mathrm{d} M_{2}(x)}{\mathrm{d} x}=V_{2}(x)-b_{2} y_{2} \tau(x) \quad \text { and } \\
& \frac{\mathrm{d} V_{2}(x)}{\mathrm{d} x}=b_{2} \sigma(x)
\end{aligned}
$$

Substituting the derivative of equations (43) and (44) into the fourth derivative from the normal stress obtained by the equation (40), gives,

$$
\begin{aligned}
\frac{\mathrm{d}^{4} \sigma_{n}(x)}{\mathrm{d} x^{4}} & +\frac{E_{a} b_{2}}{t_{a}}\left(\frac{1}{E_{1} I_{1}}+\frac{D_{11}^{x}}{b_{2}}\right) \sigma_{n}(x) \\
& +\frac{E_{a} b_{2}}{t_{a}}\left(\frac{y_{1}}{E_{1} I_{1}}-\frac{D_{11}^{x}}{b_{2}}\right) \frac{\mathrm{d} \tau(x)}{\mathrm{d} x}+\frac{q E_{a}}{t_{a} E_{1} I_{1}}=0
\end{aligned}
$$

The general solution to this fourth-order differential solution is

$$
\begin{aligned}
& \sigma_{n}(x)=\mathrm{e}^{-\beta x}\left[C_{1} \cos (\beta x)+C_{2} \sin (\beta x)\right] \\
& \quad+\mathrm{e}^{\beta x}\left[C_{3} \cos (\beta x)+C_{4} \sin (\beta x)\right]-n_{1} \frac{\mathrm{d} \tau(x)}{\mathrm{d} x}-n_{2} q
\end{aligned}
$$


Table 1. Geometric and material parameters.

\begin{tabular}{lcccccc}
\hline Component & Width $(\mathrm{mm})$ & Depth $(\mathrm{mm})$ & $E_{11}(\mathrm{GPa})$ & $E_{22}(\mathrm{GPa})$ & $G_{12}(\mathrm{GPa})$ & Coefficient $v$ \\
\hline Structure & 200 & 300 & 30 & 30 & - & 0.18 \\
(FRP) plate & 200 & 4 & 100 & 10 & 5 & 0.28 \\
(GFRP) plate & 200 & 4 & 50 & 10 & 5 & 0.28 \\
(Steel) plate & 200 & 4 & 200 & 10 & 5 & 0.3 \\
Adhesive & 200 & 4 & 3 & - & - & 0.35 \\
\hline
\end{tabular}

For large values of $x$, the normal stress approaches zero, and it results $C_{3}=C_{4}=0$, the general solution follows equation (47),

$$
\begin{aligned}
\sigma_{n}(x)= & \mathrm{e}^{-\beta x}\left[C_{1} \cos (\beta x)+C_{2} \sin (\beta x)\right] \\
& -n_{1} \frac{\mathrm{d} \tau(x)}{\mathrm{d} x}-n_{2} q \\
\beta= & \sqrt[4]{\frac{E_{a} b_{2}}{4 t_{a}}\left(\frac{1}{E_{1} I_{1}}+\frac{D_{11}^{x}}{b_{2}}\right)} \\
n_{1}= & \left(\frac{y_{1} b_{2}-D_{11}^{x} y_{2} E_{1} I_{1}}{D_{11}^{x} E_{1} I_{1}+b_{2}}\right)
\end{aligned}
$$

$C_{1}$ et $C_{2}$, are constant which will be determined by the boundary conditions that follows special cases of Smith and Teng's equations (70) and (71).

$$
\begin{aligned}
C_{1}= & -\frac{n_{3}}{2 \beta^{3}} \tau(0)+\frac{n_{1}}{2 \beta^{3}}\left(\left.\frac{\mathrm{d}^{4} \tau(x)}{\mathrm{d} x^{4}}\right|_{x=0}+\left.\beta \frac{\mathrm{d}^{3} \tau(x)}{\mathrm{d} x^{3}}\right|_{x=0}\right) \\
& -\frac{E_{a}}{2 \beta^{3} t_{a}} \frac{1}{E_{1} I_{1}}\left(V_{T}(0)+\beta M_{T}(0)\right) \\
C_{2}=- & \left.\frac{n_{1}}{2 \beta^{2}} \frac{\mathrm{d}^{3} \tau(x)}{\mathrm{d} x^{3}}\right|_{x=0}-\frac{E_{a}}{2 \beta^{2} t_{a}} \frac{1}{E_{1} I_{1}} M_{T}(0) \\
n_{3}= & \frac{E_{a} b_{2}}{t_{a}}\left(\frac{y_{1}}{E_{1} I_{1}}-\frac{y_{2} D_{11}^{x}}{b_{2}}\right) .
\end{aligned}
$$

\section{Numerical solution}

In this research, the numerical solution shows that the interfacial stresses are significant at the end of the FRP plate and, their values decrease after a limit of $300 \mathrm{~mm}$. All the solutions used to identify the interfacial stresses converge and according to several approaches analyzed in several literatures. The uniformly distributed load is $50 \mathrm{kN} . \mathrm{m}^{-1}$ and, the coefficient of expansion of the beam has a middle value $10.2 \times 10^{-6} /{ }^{\circ} \mathrm{C}$. A summary of the geometric and material properties is given in Table 1.

\section{Comparison of analytical solutions}

\subsection{First configuration}

In this section, numerical results of the present solutions are presented to study the effect of various parameters on the distributions of the interfacial stresses, such as

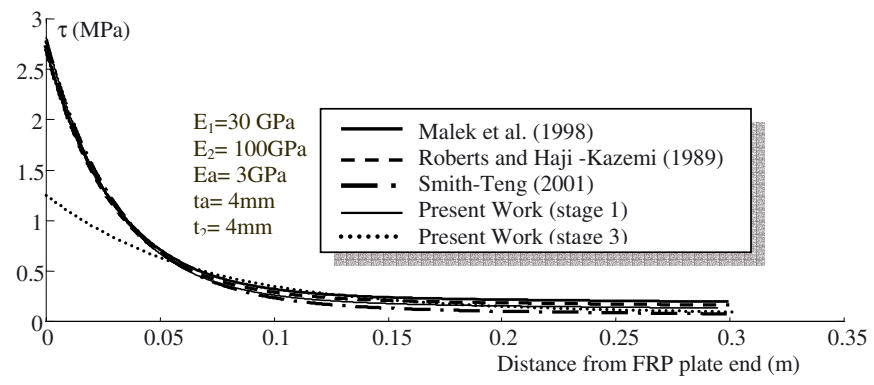

Fig. 3. Comparison of interfacial shear stress for beam with a bonded FRP soffit plate.

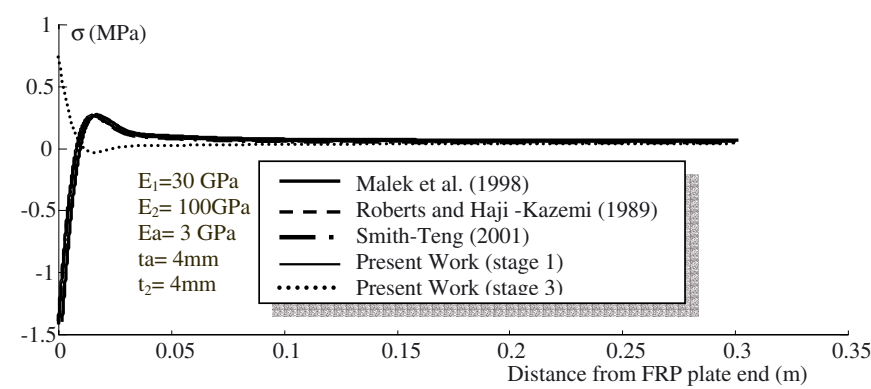

Fig. 4. Comparison of interfacial normal stress for beam with a bonded FRP soffit plate.

Stage 1: Mechanical load. Stage 2: Mechanical and thermal load. Stage 3: Mechanical and shear deformations effect. Stage 4: Mechanical and thermal load and shear deformations effect. Stage 5: Thermal and shear deformations effect.

the geometric and physical parameters (stages 1, 2, 3, 4 and 5). The results are intended to demonstrate the main characteristics of interfacial stress distributions in these strengthened beams, Table 2.

The method is verified by comparing it to the closedform solution presented by Malek et al. [14], Roberts and Haji-Kazemi [9] and by Smith and Teng [21]. The closed-form solution given by Smith and Teng, improves the more accurate widely applicable solution, particularly when the flexural stiffness of the bonded plate becomes significant. The results obtained using the method developed by these researches together with the present closedform solution for interfacial shear and normal stresses are shown in Figures 3 and 4. As can be seen from the presented results, it is excellent agreement between theses methods. 
Table 2. Comparison of the maximum interfacial stresses.

\begin{tabular}{|c|c|c|c|c|c|c|}
\hline \multicolumn{7}{|c|}{ Comparison of the peak interfacial shear and normal stresses: $\left(E_{2}=100 \mathrm{GPa}\right)$} \\
\hline \multirow[b]{2}{*}{ Theory } & \multicolumn{2}{|c|}{$E_{1}=30 \mathrm{GPa}$} & \multicolumn{2}{|c|}{$E_{1}=50 \mathrm{GPa}$} & \multicolumn{2}{|c|}{$E_{1}=100 \mathrm{GPa}$} \\
\hline & $\tau(\mathrm{MPa})$ & $\sigma(\mathrm{MPa})$ & $\tau(\mathrm{MPa})$ & $\sigma(\mathrm{MPa})$ & $\tau(\mathrm{MPa})$ & $\sigma(\mathrm{MPa})$ \\
\hline Roberts & 2.604 & 1.567 & 1.552 & 0.923 & - & - \\
\hline \multicolumn{7}{|l|}{ Roberts and } \\
\hline Haji-Kazemi & 2.591 & 1.500 & 1.962 & 1.060 & - & - \\
\hline Malek et al. & 2.597 & 1.563 & 1.499 & 0.871 & - & - \\
\hline Smith and Teng & 2.740 & 1.484 & 1.796 & 0.930 & - & - \\
\hline \multicolumn{7}{|l|}{ Present work } \\
\hline Stage 1 & 2.785 & 1.306 & 1.883 & 0.889 & 1.052 & 0.499 \\
\hline \multicolumn{7}{|l|}{ Present work } \\
\hline Stage 2 & 17.807 & 8.194 & 18.570 & 8.598 & 19.428 & 9.042 \\
\hline \multicolumn{7}{|l|}{ Present work } \\
\hline Stage 3 & 1.230 & 0.611 & 0.987 & 0.485 & 0.675 & 0.329 \\
\hline
\end{tabular}
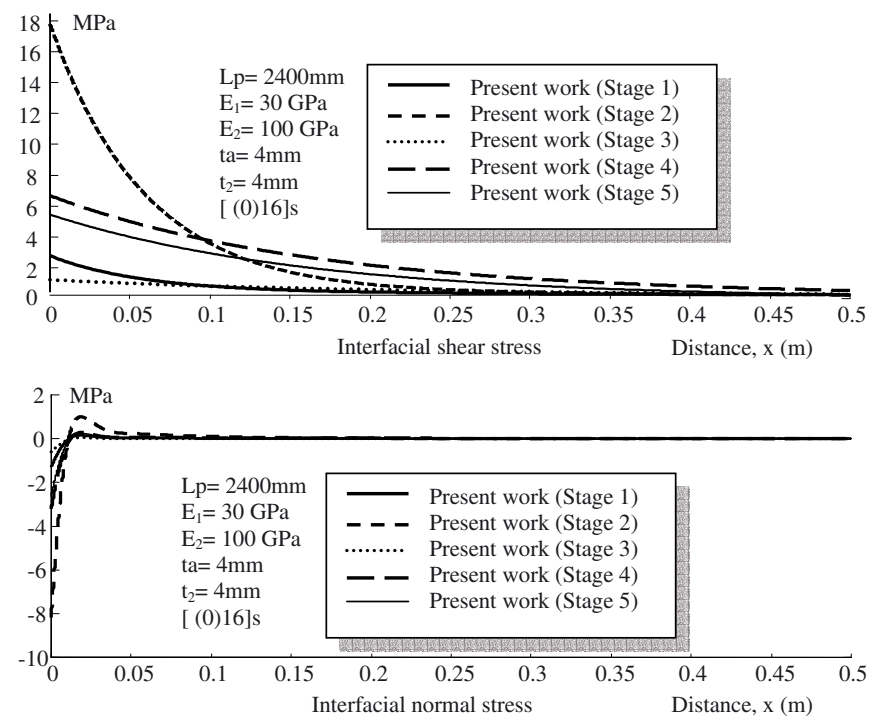

Fig. 5. Comparison of interfacial stresses along the bond line for the FRP-strengthened beam with different configurations: $[(0) 16] \mathrm{s}$.

Overall, the predictions of the different solutions agree closely with each other and we noticed that the bending deformation and the axial load are the determining elements in the assembly structures but the shear deformations are the dominant parameters in the retrofit operations of the structures. This shear lag effect that characterizes the shear deformation of the beam permits to reduce the value of the stresses. In this study, thermal loads coupled with shear deformations and mechanical load are the dominant parameters in the retrofit operations of the structures, particularly in design of civil structures and rehabilitation. This originality research is described in terms by the analysis of the stage 1 , stage 2 , stage 3 and the stage 4 , and is likely to be the most accurate for the interfacial stresses as given below, is plotted in Figures 5 and 6 . While taking into account the shear lag effect, the structure absorbs a certain proportion of the interfacial stresses, what is defined well in Figures 3-6
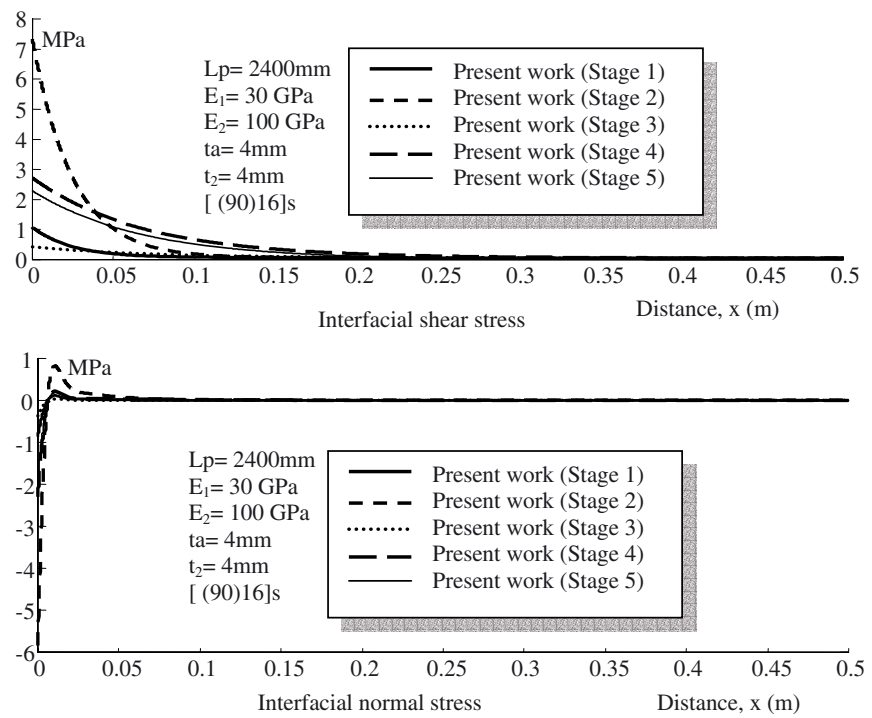

Fig. 6. Comparison of interfacial stresses along the bond line for the FRP-strengthened beam with different configurations: $[(90) 16] \mathrm{s}$.

"stage 3", therefore, the effect of shear lag decreases the value of the interfacial stresses.

The effect of thermal load and shear deformation on the interfacial stresses leads to significant value in the peak interfacial stresses comparatively to the shear deformation effect, but leads to significant reduction value comparatively to thermal effect and FRP plate fibre orientation.

\subsection{Second configuration}

In this section, numerical results of the present solutions are presented with the effect of various parameters on the distributions of the interfacial stresses in beam bonded with an FRP plate, like mechanical and thermal load, shear deformations and FRP plate fibre orientation effect. These parameters influence the maximum values of 
Table 3. Influence of the physical properties of the adherends: present work: stage 4 .

\begin{tabular}{|c|c|c|c|c|c|c|}
\hline \multicolumn{7}{|c|}{ Comparison of the peak interfacial shear and normal stresses } \\
\hline \multirow[b]{2}{*}{ Theory } & \multicolumn{2}{|c|}{$E_{2}=50 \mathrm{GPa}$} & \multicolumn{2}{|c|}{$E_{2}=100 \mathrm{GPa}$} & \multicolumn{2}{|c|}{$E_{2}=200 \mathrm{GPa}$} \\
\hline & $\tau(\mathrm{MPa})$ & $\sigma(\mathrm{MPa})$ & $\tau(\mathrm{MPa})$ & $\sigma(\mathrm{MPa})$ & $\tau(\mathrm{MPa})$ & $\sigma(\mathrm{MPa})$ \\
\hline $\mathrm{RC}$ beam & 5.368 & 3.074 & 6.688 & 3.233 & 7.839 & 3.196 \\
\hline AL beam & 6.568 & 3.738 & 8.487 & 4.077 & 10.372 & 4.205 \\
\hline Steel beam & 8.426 & 4.757 & 11.314 & 5.399 & 14.558 & 5.871 \\
\hline
\end{tabular}
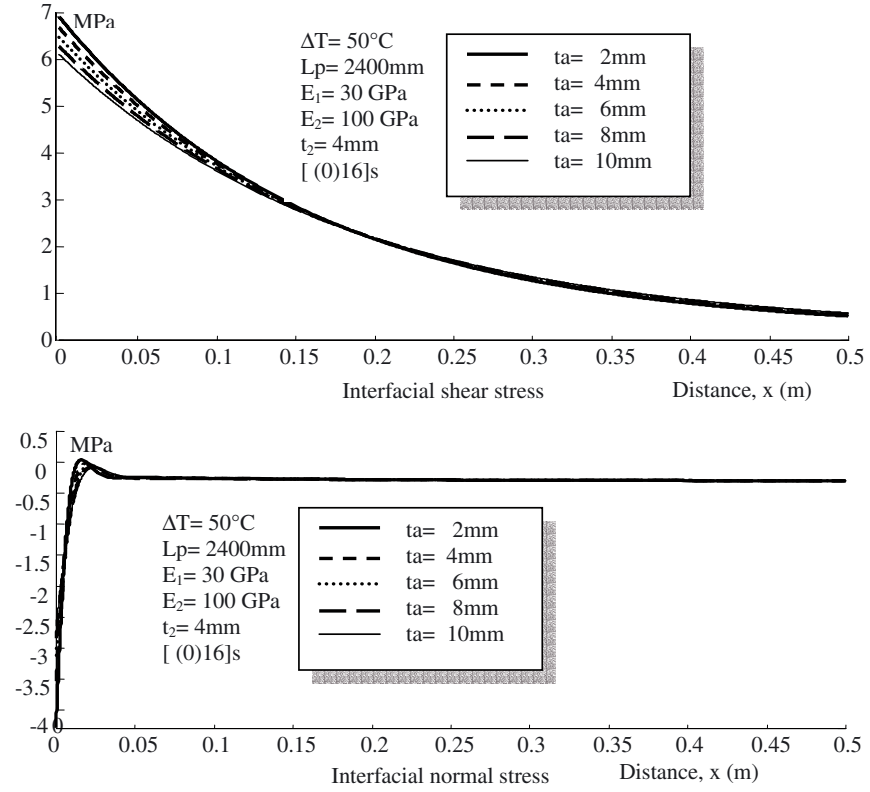

Fig. 7. Effect of adhesive layer thickness on interfacial stresses in FRP strengthened beam: present work: stage 4 .

the shear and the normal stresses in the bonding zone, as plotted in Figures 7-13. For retrofitted beams, the most important terms are considered, as the thickness of the adhesive, the shear modulus of the adhesive, the thickness, the elastic modulus of the FRP plate and the fibre orientations. We have taken into consideration the shear deformations and fibre orientation parameters in the second configuration, Table 3.

\subsubsection{Effect of adhesive layer thickness}

Figure 7 shows the effects of the thickness of adhesive layer on the interfacial stresses. It is seen that increasing the thickness of the adhesive layer leads to significant reduction in the peak interfacial stresses. The maximum adhesive stresses are reached at the plate end region and may be caused premature failure.

\subsubsection{Effect of FRP strip thickness}

Figure 8 shows the effects of the thickness of the FRP plate on the interfacial stresses. Here, five sets of the thickness, 2, 4, 6, 8, $10 \mathrm{~mm}$, are considered. It is shown that the level and concentration of interfacial stresses are influenced considerably by the thickness of FRP plate.
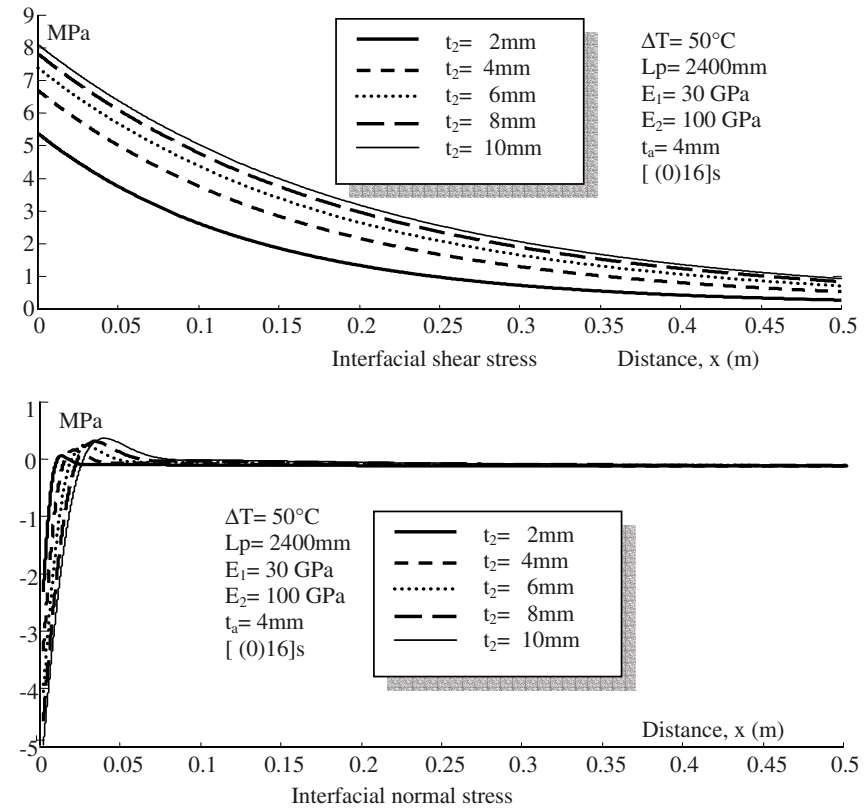

Fig. 8. Effect of FRP plate thickness on interfacial stresses in FRP strengthened beam: present work: stage 4 .
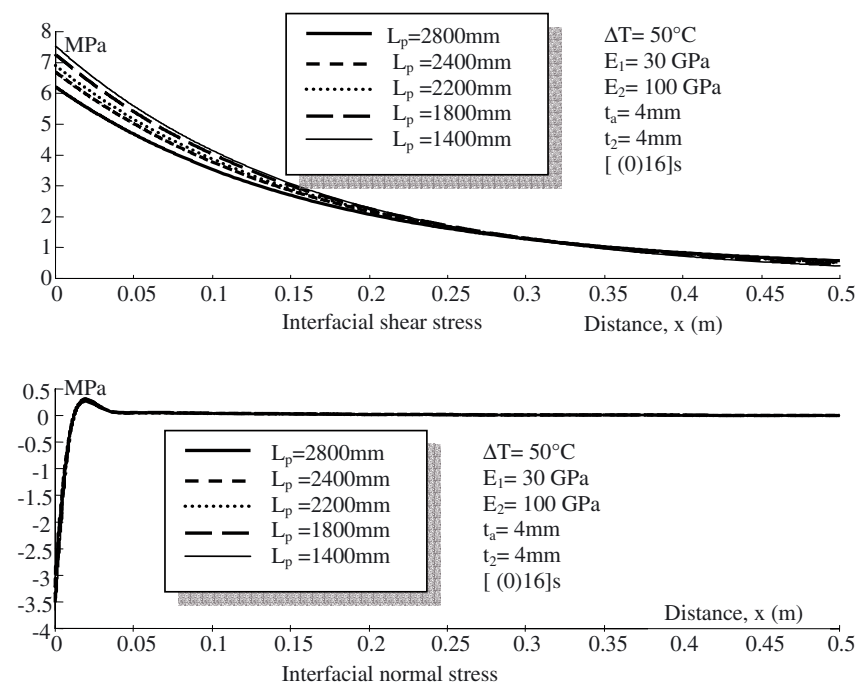

Fig. 9. Effect of FRP plate length on interfacial stresses in FRP strengthened beam: present work: stage 4 .

Thus any increase in the flexural rigidity leads to an increase in the magnitude of the edge stresses. Therefore, the fact of the smaller interfacial stress level and concentration should be one advantage of retrofitting by FRP over by steel plate. 

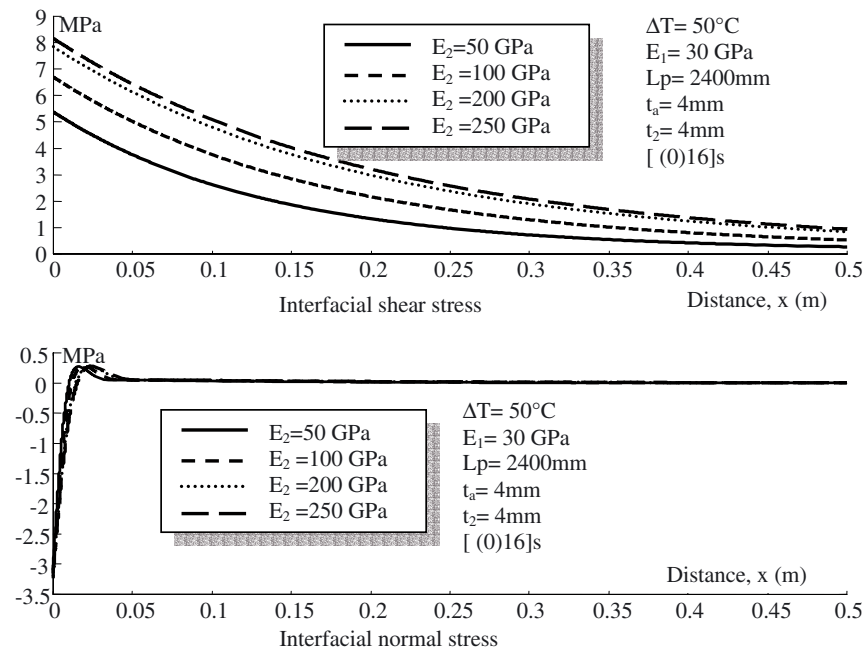

Fig. 10. Effect of plate material on interfacial stresses in FRP strengthened beam: present work: stage 4 .
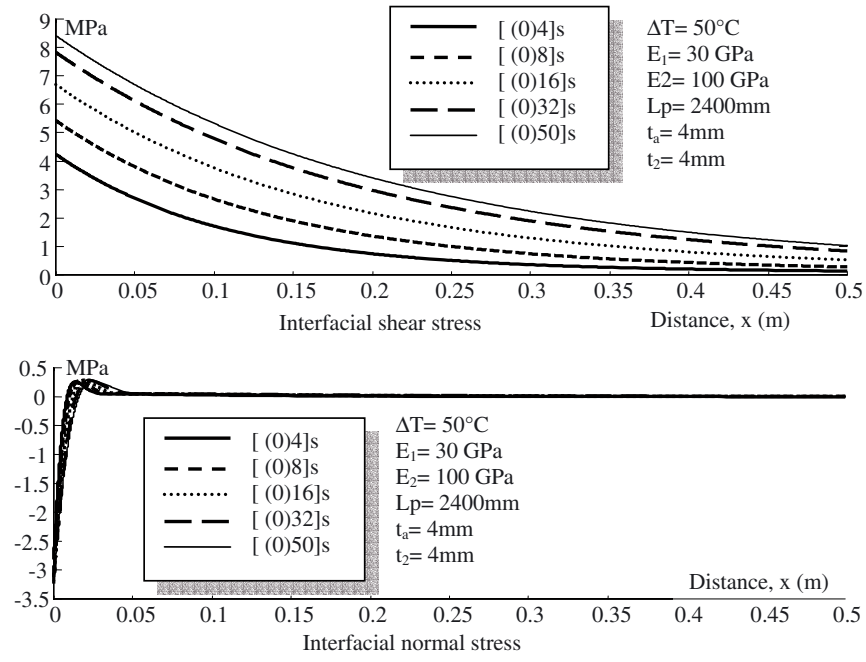

Fig. 11. Effect of number of laminate layers on interfacial stresses in FRP strengthened beam: present work: stage 4 .

\subsubsection{Effects on plate length of the strengthened beam region}

The influence of length of the strengthened beam region Lp appears in Figure 9. It is seen that, as the plate terminates further away from the support, the interfacial stresses increase significantly. This result reveals that in any case of strengthening, including cases where retrofitting is required in a limited zone of maximum bending moments at midspan, it is recommended to extend the strengthening strip as close as possible to support lines.

\subsubsection{Effect of elasticity modulus of the strengthening plate}

Figure 10 gives interfacial normal and shear stresses for the RC beam bonded with GFRP plate, FRP plate,
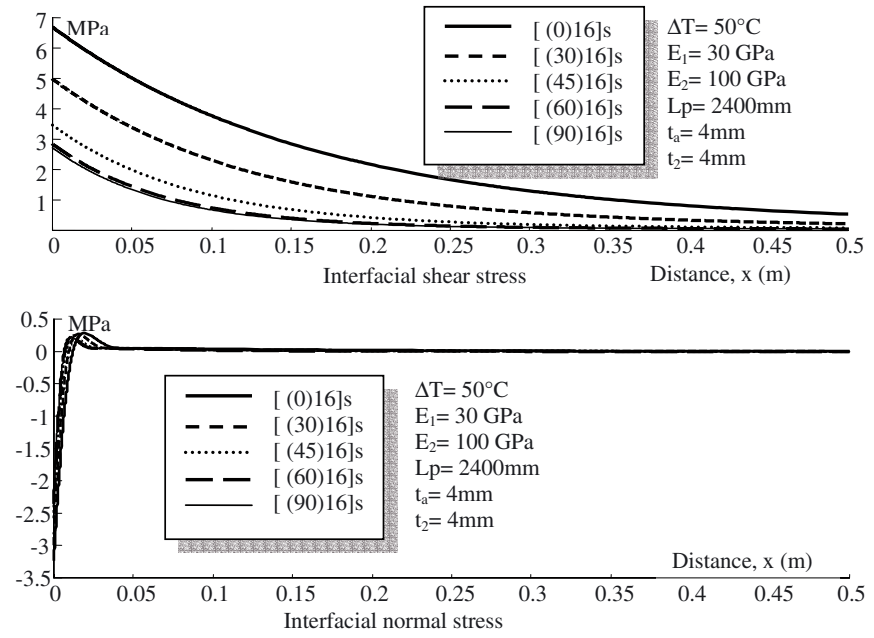

Fig. 12. Effect of fibre orientations on interfacial stresses in FRP strengthened beam: present work: stage 4 .
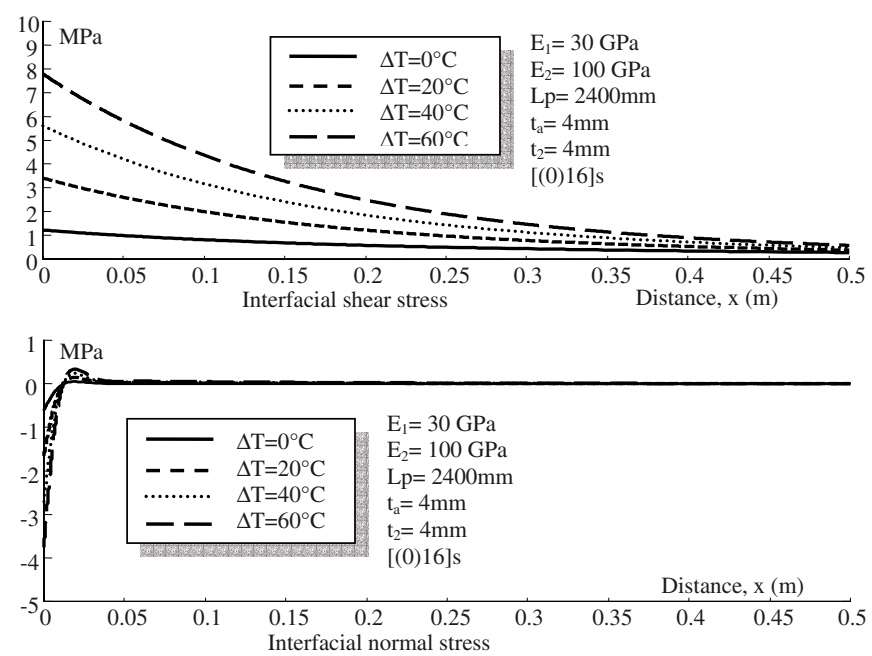

Fig. 13. Effect of temperature variation on interfacial stresses in FRP strengthened beam: present work: stage 4 .

steel plate and CFRP plate, respectively, which demonstrate the effect of adhesive and plate material properties on interfacial stresses. The results show that, as the plate material became softer, the interfacial stresses become smaller. The position of the peak interfacial shear stress moves closer to the free edge as the plate becomes softer and the adhesive layer becomes thinner.

\subsubsection{Effect of the number of laminate layers}

Figure 11 compares the maximum adhesive shear and normal stresses with different numbers of laminate layers. According to the predicted results, the adhesive stresses increase with increasing numbers of laminate layers. The maximum adhesive peel-off stress is reached at the plate end region and then rapidly decreases to a negative value in general. Therefore, by knowing the number of laminate layers, the maximum adhesive stresses at the plate end regions can be evaluated. 


\subsubsection{Effect of the fibre orientations}

The use of the FRP plate with different fibre orientations results changes the effective thickness effect of the composite plate. Having high strength fibres aligned in the beam direction would maximise the thickness of the plate, while having the fibres aligned perpendicularly to the beam axis would greatly reduce the plate thickness. The maximum adhesive stresses increases with increasing alignment of all high strength fibres in the composite plate in beam's longitudinal direction $x$. The effects on adhesive stresses with different fibre orientation from the beam's longitudinal direction are shown in Figure 12.

\subsubsection{Effect of the temperature expansion of the structure}

The influence of temperature of the strengthened beam region $\Delta T$ appears in Figure 13. The maximum adhesive stresses also increase with increasing temperature in the structure. Another important problem in beams reinforced with FRP plates is the large difference between the coefficients of thermal expansion. Denton [31] indicated substantial longitudinal shear stresses and normal tensile stresses can be developed in the adhesive layer near the ends of the FRP plate as a result of the difference between the thermal coefficients, (the coefficient of thermal expansion of the beam is of $10.2 \times 10^{-6} /{ }^{\circ} \mathrm{C}$, whereas the coefficient of thermal expansion of the plate is nearly zero). For the $50{ }^{\circ} \mathrm{C}$ temperature increase, the stresses in the adhesive at the end of the plate would be close to the failure stress.

\section{Conclusion}

A simple closed-form solution to calculate the interfacial stresses of retrofitted plated beams under thermal and mechanical loads coupled with the shear deformations effect has been presented in this paper, and a simple numerical solution has also been given for the case of the FRP plate's fibre orientations. Shear stress distribution and the level of the interface of reinforced materials are considered by taking into account "the thermal load" coupled with "Shear deformations", and are presented in this work, with the various configurations of structures. The preceeding studies neglected the term of the thermal effects coupled with the shear deformations of the structures. The method presented can be used to predict the distribution of interfacial stresses when cracks are present along the structure. Throughout this study, we can conclude that the proposed theoretical model is able to determine the shear and peel-off stresses of the adhesive layer of the structure reinforced by composite laminate layers under externally load coupled with the thermal and shear deformations model. Different fibre arrangements inside the FRP laminate are considered in evaluating the stress mechanism of the strengthened structures. The effective modulus of the externally bonded FRP plate increases with increasing percentage of fibre aligned in the beam's longitudinal direction. The maximum shear and normal stresses increase with increasing moduli of the FRP plate and adhesive materials and decreasing thickness of the adhesive layer.

The design of the FRP-strengthened beam system should consider the resultant adhesive shear and normal stresses, the axial and moment stresses in the FRP plate and the allowable shear stress and stress intensity factor of the beam due to the external applied load, and it should optimise the fibre orientation and laminate arrangement in order to achieve the maximum strengthening capacity.

All of the existing solutions include the bending and the axial deformations in the structure in the bonded plate with inclusion of other terms, but the new solution includes the effects of all solicitations terms like the shear deformations and the thermal loads coupled with mechanical load and the fibre orientations. The new solution can be applied to structures made of all kinds of materials bonded with the FRP plate, where the rigidity of the beam and the plate are more comparable. The interfacial stresses are influenced by the geometry and material parameters, such as, shear modulus and thickness of adhesive layer, elastic modulus and thickness of FRP plate in range of the different degrees.

In future, more extensive work is required to solve the problems caused by temperature, vandalism and fatigue damage of the interface of FRP-strengthened structure.

Acknowledgements. Both authors acknowledge all staff that works in the laboratory of the materials and hydrology of the Faculty of the engineer's Sciences and the financial support from the University of Sidi Bel Abbès, in particular for the availability and facility to carry out this work.

\section{References}

[1] W. An, H. Saadatmanesh, M.-R. Ehsani, RC beam strengthened with FRP plates: II. Analysis and parametric study, ASCE J. Struct. Eng. 117 (1991) 3434-3455

[2] F. Seibel, M.-J.-N. Priestley, G.-A. Hegemier, Seismic retrofit of RC columns with continuous carbon fibre jackets, J. Comp. Const. 1 (1997) 52-62

[3] A. Hamoush, S.-H. Ahmed, Concrete crack repair by stitches, J. Mater. Struct. 30 (1997) 418-423

[4] J.-S.-E. Connor, New York State gives FRP's a try: Structure Magazine, Summer 1999

[5] K.-T. Lau, L.-M. Zhou, C.-H. Woo, Strengthening and strain monitoring concrete structures using fibreglass composites and FBG sensor, J. Mater. Sci. Res. Int. 5 (1999) 216-221

[6] Z. Wu, T. Matsuzaki, K. Tanabe, Interface crack propagation in FRP-Strengthened concrete structures. Non-metallic (FRP) reinforcement for concrete structures, Japan concrete inst. 1 (1997) 319-326

[7] K.-R. Jones, R.-N. Swamy, A. Charif, Plate separation and anchorage of reinforced concrete beams strengthened by epoxy-bonded steel plates, struct. Eng. 66 (1988) $85-94$ 
[8] T.-M. Roberts, Approximate analysis of shear and normal stress concentrations in adhesive layer of plated RC beams, Struct. Eng. London 67 (1989) 229-233

[9] T.-M. Roberts, H. Haji-Kazemi, Theoretical study of the behaviour of reinforced concrete beams strengthened by externally bonded steel plates, Proc. Int. Civil Eng. 87 (1989) 39-55

[10] D.-J. Oehlers, Reinforced concrete beams with plates glued to their soffits, J. Strut. Eng. ASCE 118 (1992) 2023-2038

[11] M.-H. Baluch, Y.-N. Ziraba, A.-M. Sharif, G.-J. Al-Sulaimani, Shear strength of plated RC beams, Mag. Concr. Res. 47 (1995) 369-374

[12] M. Raoof, J.-A. El-Rimawi, M.-A.-H. Hassanen, Theoretical and experimental study on externally plated RC beams, Eng. Strut. 22 (2000) 85-101

[13] F. Yuan, J.-G. Teng, R. Seracino, Z.-S. Wu, Full-Rang behaviour of FRP- to-concrete bonded joints, Eng. Struct. 26 (2004) 553-565

[14] A.-M. Malek, H. Saadatmanesh, M.-R. Ehsani, Prediction of failure load of R/C beams strengthened with FRP plate due to stress concentration at the plate end, ACI Strut. J. 95 (1998) 142-152

[15] H. Saadatmanesh, A.-M. Malek, Design guidelines for flexural strengthening of RC beams with FRP plates, J. Compos. Construct. ASCE 2 (1998) 158-164

[16] T.-C. Triantafillou, C.-P. Antonopoulos, Design of concrete flexural members strengthened in shear with FRP, ASCE J. Compos. Construct. 4 (2000) 198-205

[17] U. Meier, R. Betti (eds.), Recent Advances in Bridge Strengthening, Proc. US-Canada- Europe Workshop, Dubendorf 1997, EMPA

[18] J.-F. Chen, J.-G. Teng, Anchorage strength models for FRP and steel plates bonded to concrete, ASCE J. Struct. Eng. 127 (2000) 784-791

[19] B. Gao, C.-K.-Y. Leung, J.-K. Kim, Prediction of concrete cover separation failure for RC beams strengthened with CFRP strips, Eng. Struct. 27 (2005) 1771-1789
[20] L. Ascione, L. Feo, Modelling of composite/concrete interface of RC beams strengthened with composite laminates. Compos: Part B 31 (2000) 535-540

[21] J.-G. Smith, J. Teng, Interfacial stresses in plated beams, Eng. Struct. 23 (2001) 857-871

[22] K.-T. Lau, P.-K. Dutta, L.-M. Zhou, Mechanics of bond in a FRP boned concrete beam, J. compos. part B 32 (2001) 491-502

[23] O. Rabinovich, Y. Frostig, Closed-from high order analysis of RC beams strengthened with FRP J. Compos. Construct. ASCE 4 (2000) 65-74

[24] O. Rabinovich, Y. Frostig, On edge stresses control in strengthened RC beams with FRP strips: adhesive layer profile effect, J. Eng. Mech. ASCE 127 (2001) 317-325

[25] O. Rabinovich, Y. Frostig, Delamination failure of RC beams strengthened with FRP strips: a closed-form high order and fracture mechanics approach, J. Eng. Mech. ASCE 127 (2001) 852-861

[26] H.-S. Shen, J.-G. Teng, J. Yang, Interfacial stresses in beams and slabs bonded with a thin plate, J. Eng. Mech. ASCE 127 (2001) 399-406

[27] M.-Y. Tsai, D.-W. Oplinger, Improved theoretical solutions for adhesive lap joint, Int. J. solids struct. 35 (1998) $1165-1185$

[28] A. Tounsi, Improved theoretical solution for Interfacial stresses in concrete beams strengthened with FRP plate, J. Solids Struct. 43 (2006) 4154-4174

[29] C.-T. Herakovich, Mechanic of fibrous composites, Wiley USA, 1998

[30] M.-W. Hyer, Stress Analysis of fibre-reinforced composite material, McGraw Hill, USA, 1998

[31] S.-N. Denton, Analysis of stresses developed, in FRP plated beams due to thermal effects, in: Proceeding of the conference on composites in civil engineering, Hong Kong, 2001, pp. 527-536 